Chapman University

Chapman University Digital Commons

$5-15-2012$

\title{
From the Womb to the Tomb: The Role of Transfers in Shaping the Evolved Human Life History
}

\author{
Michael Gurven \\ University of California, Santa Barbara \\ Jonathan Stieglitz \\ University of New Mexico \\ Paul L. Hooper \\ University of New Mexico \\ Cristina Gomes \\ University of California, Santa Barbara \\ Hillard Kaplan \\ Chapman University, hkaplan@chapman.edu
}

Follow this and additional works at: https://digitalcommons.chapman.edu/esi_pubs

Part of the Biological and Physical Anthropology Commons, Economic Theory Commons, Ethnic Studies Commons, Latin American Studies Commons, Other Anthropology Commons, Other Economics Commons, and the Social and Cultural Anthropology Commons

\section{Recommended Citation}

Gurven, M., Stieglitz, J., Hooper, P. L., Gomes, C., \& Kaplan, H. (2012). From the womb to the tomb: the role of transfers in shaping the evolved human life history. Experimental Gerontology, 47(10), 807-813.

https://doi.org/10.1016/j.exger.2012.05.006 
Published in final edited form as:

Exp Gerontol. 2012 October ; 47(10): 807-813. doi:10.1016/j.exger.2012.05.006.

\title{
From the womb to the tomb: the role of transfers in shaping the evolved human life history
}

\author{
Michael Gurven, \\ Department of Anthropology, University of California-Santa Barbara, Santa Barbara, CA 93106, \\ TELEPHONE: 805-893-2202, FAX: 805-893-8707
}

Jonathan Stieglitz, Department of Anthropology, University of New Mexico, Albuquerque, NM 87131

Paul L. Hooper, Department of Anthropology, University of New Mexico, Albuquerque, NM 87131

Cristina Gomes, and Institute of Social, Behavioral and Economic Research, University of California, Santa Barbara, CA, 93106; Universidad Simón Bolivar, Departamento de Biología de Organismos, Caracas, Venezuela

\section{Hillard Kaplan \\ Department of Anthropology, University of New Mexico, Albuquerque, NM 87131}

Michael Gurven: gurven@anth.ucsb.edu; Jonathan Stieglitz: j0nathan@unm.edu; Paul L. Hooper: phooper@unm.edu; Cristina Gomes: gomes@isber.ucsb.edu; Hillard Kaplan: hkaplan@unm.edu

\section{Abstract}

Humans are the longest living and slowest growing of all primates. Although most primates are social, humans are highly cooperative and social in ways that likely co-evolved with the slow human life history. In this paper we highlight the role of resource transfers and non-material assistance within and across generations in shaping low human mortality rates. The use of complex cooperative strategies to minimize risk is a necessary precursor for selecting further reductions in mortality rate in late adulthood. In conjunction with changes in the age-profile of production, the impacts of resource transfers and other forms of cooperation on reducing mortality likely played an important role in selection on post-reproductive lifespan throughout human evolution. Using medical data and ethnographic interviews, we explore several types of common risks experienced by Tsimane forager-horticulturalists, and quantify the types and targets of aid. Our results illustrate the importance of transfers in several key domains and suggest that the absence of transfers would greatly increase human mortality rates throughout the life course.

\section{Keywords}

intergenerational transfers; sharing; life history evolution; longevity; Tsimane

(C) 2012 Elsevier Inc. All rights reserved.

Correspondence to: Michael Gurven, gurven@anth.ucsb.edu.

Publisher's Disclaimer: This is a PDF file of an unedited manuscript that has been accepted for publication. As a service to our customers we are providing this early version of the manuscript. The manuscript will undergo copyediting, typesetting, and review of the resulting proof before it is published in its final citable form. Please note that during the production process errors may be discovered which could affect the content, and all legal disclaimers that apply to the journal pertain. 


\section{Introduction}

Traditional life history theory requires that personal energy budgets cover the expenses of growth, maintenance and reproduction, such that body size and resource production are often highly significant predictors of the pace and timing of fundamental life processes (Stearns 1992). Social animals, however, can lend and borrow critical resources in ways that inflate budgets and allow investments that otherwise would not be possible given a reliance on one's own efforts. The ability to lend and borrow resources and provide and solicit other forms of aid within and across generations (i.e. intertemporal budgets) can strongly impact selection on age-schedules of mortality and fertility, and prolong lifespan (Amdam and Page 2005; Kaplan et al. 2000; Lee 2003; Robson and Kaplan 2003). Resource transfers improve the likelihood that juveniles reach adulthood and reduce adult mortality, thereby extending adult lifespan. Fitness impacts of transfers made by donors of different ages determine the value of being alive at those ages in ways that differ from the standard Hamiltonian formulation of the "force of selection" which includes direct reproduction but ignores transfers (Baudisch 2005; Bourke 2007). Transfers are often costly to the donor and therefore require that the donor recoups the loss by receiving fitness benefits through shared relatedness, future cooperative exchange, or direct reproduction (Hamilton 1964; Trivers 1971).

Several recent models have included intergenerational transfers that co-evolve with lifespan in social species (Cyrus Chu and Lee 2006; Kaplan and Robson 2002; Kaplan and Robson 2009; Lee 2003). These models make claims about the magnitude and direction of transfers, but assume an asexual population, and so kinship is not a part of these models. Nor are transfers specifically defined, only referring to energy flow, production and fitness in a general way. In order to further develop these models, empirical information is needed on material and non-material transfers in human populations living under similar conditions in which our ancestors evolved. Extant populations of hunter-gatherers and horticulturalists are energy-limited and physically active, experience natural fertility and lack access to public sanitation, health care and other modern services that increase welfare. Information on the kinds and frequency of risks afflicting humans in such an environment, and the extent to which transfers help overcome harmful consequences of these risks, is critical for understanding how the human life history evolved.

To date, most empirical work on transfers has focused on food exchange (Gurven 2004; Winterhalder 1997). Hunter-gatherer diets are often characterized by high levels of acquisition variance due to luck, resource mobility and differences in skill. For example, the probability that a Hadza, Hiwi and Ache hunter is successful on a hunt is about 4\%, 35\%, and 60\%, respectively (Hill and Hurtado 2009). Entry into this production niche therefore carries the cost of many unsuccessful foraging attempts. Such high variance is common to most foraging economies because humans subsist largely on difficult-to-acquire resources including meat, fish and extracted items like larvae, honey and roots. It often takes years for adolescents to develop foraging proficiency, resulting in another form of acquisition variance due to variation in age and ability. The human foraging niche therefore fosters a high level of dependency amongst juveniles for many years. In foraging and mixed foraging-horticultural economies, individuals do not produce more food than they consume until their late teens (Gurven and Kaplan 2006; Kaplan 1994; Lee 1996) ${ }^{1}$. However, the risk of food shortfalls occurs at all ages, as even adults in their peak production years cannot consistently meet the daily caloric needs of their large families.

${ }^{1}$ Agricultural tasks appear to increase the production of teenagers and lower the age of caloric independence to the mid-teens (Kramer 2002) 
The human foraging niche allows the possibility of greater risk of food shortfalls over the life course, but also includes a variety of other important risks that can impact fitness. Illness left untreated can lead to cascading morbidity and possibly death, and often impairs the ability to produce food or perform other important daily tasks. Death or divorce renders dependent children vulnerable to food shortage, disease and lack of protection, and renders adults vulnerable to labor shortage. Conflict left unresolved, especially among kin, can result in fractured social and sharing networks, migration, fighting, and homicide. Theft and breakage of important tools, possessions or other resources can potentially disrupt production and often requires substantial costs to replace. Human cooperation and sociality have evolved to reduce risk in these fitness-relevant domains. While instances of non-food transfers in social species are not rare (e.g. Carey and Gruenfelder 1997; Galef 2001), humans may be unique in the breadth and volume of transfers across different domains.

This paper examines sources of risk and cooperative solutions to risk reduction among Tsimane forager-horticulturalists in lowland Bolivia. In addition to the basic problem of daily food shortfalls, we focus on the prevalent problems of longer-term food shortages, illness and disability, parental and spousal loss due to death or divorce, social conflict and tool loss. This is the first systematic survey of multiple risks and transfers in an indigenous population living under fairly traditional conditions. Study of these populations can act as an important lens for gaining insight into past conditions and selection pressures that shaped the evolved human life history. We argue that the cooperative solutions to common problems helped humans survive from birth to adulthood, and helped adults live longer lives. We expect: (1) the level of risk to be non-trivial across the domains investigated, (2) the level of support to be substantial, with (3) targeting of close kin, and (4) substantial contributions from adults over the age of 40 , which increase the fitness value of being alive at late ages, including during the post-menopausal life stage.

\section{Material and Methods}

The Tsimane Health and Life History Project (THLHP) ${ }^{2}$ aims to understand the rate of actuarial and physiological senescence in ecological and cultural context. Tsimane are Bolivian forager-horticulturalists who subsist from horticulture (plantains, manioc, rice and corn), hunting, fishing and fruit gathering. Closely related families often reside together in residential clusters, which act as units of cooperative production and consumption. Tsimane have relatively short life expectancy, high work load, and minimal access to modern amenities such as healthcare, sanitation and electricity (Gurven et al. 2007). THLHP employs research methods commonly utilized by epidemiologists, biodemographers, and anthropologists. All methods are approved by Human Subjects Review Boards at UCSB and UNM, and approved by the Tsimane government council, village leaders and study participants.

\subsection{Shocks interview}

A detailed retrospective interview was administered to 671 individuals age $16+$ by a bilingual (Spanish-Tsimane) research assistant from March 2005 to July 2006. Participants were queried about numerous aspects of recent illness, crop failure, theft, residence, divorce and conflict, including frequency over a specified time interval, impact of the loss, and type and amount of assistance received and given. Kinship among donors and recipients of assistance was recorded, and ages were assigned to named helpers or recipients based on prior demographic analysis and census records (Gurven et al. 2007).

\footnotetext{
$2_{\text {http://www.unm.edu/ tsimane }}$
} 


\subsection{Production and sharing interview}

From January 2005 to December 2009, adults from 11 villages were interviewed once or twice per week about time allocation to work for each co-resident individual over age 6 during the previous two days ( $\mathrm{n}=1,245$ individuals). We recorded number of hours engaged in subsistence macro-categories (i.e., hunting, fishing, garden labor, foraging), specifying type of activity within each macro-category (e.g., hook and line fishing, harvesting rice, hunting with bow/arrow). For each activity per person per day we inquired about quantities produced and shared. Each family was interviewed an average of 45.5 times $(\mathrm{SD}=20.4)$, yielding a mean of 92.8 sample days per individual. For details about estimation of agespecific production, consumption and distribution, see Hooper (2011).

\subsection{Medical exam/interview}

Bolivian physicians working with bilingual Tsimane research assistants diagnosed patient illnesses during annual medical exams as part of the THLHP. Diagnoses from the International Classification of Disease (ICD-10) are grouped into gastrointestinal, respiratory, and other ailments for exams conducted from 2002-2004.

\section{Results}

\subsection{Incapacitating illness/injury}

Infections and other ailments are common occurrences, with $<10 \%$ of adults diagnosed as "healthy" in a given year (Figure 1). Common diagnoses impacting infants and children include diarrhea, pneumonias, fevers and macro-parasites; adults often suffer from osteoarthritis, respiratory infections, skin infections, common cold, urinary tract infections, and injuries such as falls and machete wounds ${ }^{3}$. Despite this high level of morbidity, many of these illnesses and injuries do not necessarily incapacitate an individual. Tsimane often work and engage in daily activities despite suffering from a variety of acute or chronic ailments. Yet 75\% (508/673) of adults report being sick enough that they could not get out of bed at least once in the past three months. Mean duration of incapacitating illness was (mean \pm S.D.) $8.7 \pm 20.9$ days, with $91 \%$ of cases lasting longer than 3 days, and included fevers, influenza, gastrointestinal infection, physical pains and swellings, accidents and injury. If representative, these results suggest that Tsimane are incapacitated by illness or injury on about $10 \%$ of all days.

Ill or injured individuals are likely to receive help in the form of food, medicinal plants, obtaining occasional Western medicines from a town pharmacy or hospital, as well as assistance with childcare and with feeding family members. Each of these forms of help was provided in the majority of incapacitating illness episodes (Table 1). Although spouses provide the most support for disabled adults, children and parents also help. Full siblings help somewhat less, but overall, kin provide the vast majority of assistance.

\footnotetext{
${ }^{3}$ Ancestral humans were probably exposed to a variety of viruses, bacteria, protozoans and parasites due to the consumption of meat and fish in our omnivorous diet (Finch and Stanford 2004). For example, molecular genetics and paleoparasitological studies show that helminthic parasites have long been a central feature of hominin disease ecology (Goncalves et al. 2003; Hurtado et al. 2008). There is growing evidence that human foragers experienced high rates of infectious disease prior to the advent of agriculture. Phylogenetic evidence for several pathogens, including smallpox, malaria and tuberculosis, (previously assumed to post-date the advent of agriculture and animal domestication) now suggests an earlier evolutionary history of exposure (see review in Pearce-Duvet 2006). Sexually transmitted diseases also likely have a long evolutionary history among humans (Donovan 2000). Antibodies to viral infections, such as herpes, Epstein-Barr and varicella have been documented in relatively isolated Amazonian groups (Black et al. 1970; Salzano and Callegari-Jacques 1988). Cytomegalovirus, pneumonias, intestinal geohelminths, herpes, hepatitis B and arboviruses have long co-existed among pre-contact Amazonian populations (Black 1975). Thus, prior to and following the advent of agriculture, humans experienced a greater pathogen burden than is currently experienced in developed nations (Hurtado et al. 2008; McKeown 1976).
} 


\subsection{Food production and need}

Hunting, fishing and horticultural activities vary in their difficulty, length of time required to learn and master, and their energetic return rates (Gurven et al. 2006; Gurven and Kaplan 2006). While the average hunt yields a per-capita return of 9,119 calories, the standard deviation is 20,199 calories, resulting in a coefficient of variation of 2.22 ( $n=3,199$ hunts). Most notably, $45 \%$ of these hunting events yield no returns; for adult men, this amounts to roughly 15 (out of average 36 hours) hours of hunting effort without gain each month. Although fishing is usually thought of as relatively low risk, our data reveal a similar level of variability as in hunting: fishing events yield a mean return of 2,218 $\pm 6,105$ calories, resulting in a coefficient of variation of $2.75 ; 21 \%$ of the 6,896 fishing events yielded no returns; this amounts to about 2.5 (out of average 14 hours) hours of fishing effort without gain by a Tsimane adult each month.

Figure 2 displays age-specific productivity (total calories produced per day) and consumption (calories consumed per day). Tsimane generate a large deficit early in life, and only start producing more than they consume by the late teens. At this point, surplus caloric production increases with age, peaks by the mid-40's, and then decreases thereafter. While we estimate that mean net production remains positive through the 70 's, this mean is not significantly greater than zero due to both declining productivity and the small sample of older adults over age 70 ( $\mathrm{n}=22$ individuals).

Although mean caloric production values in adulthood from Figure 2 suggest a surplus from ages 18 to 80 , the burden of feeding multiple, dependent offspring creates net deficits in caloric production within nuclear families until parents reach about age 40 (Hooper 2011). In terms of net family production, surpluses are therefore restricted to adults from age 40 to 80 , on average. Focusing only on mean net production, however, can still be misleading. Of the 195 families comprising our production sample, 53\% had negative net production: their cumulative actual production is less than their estimated caloric needs based on age, sex and weight (although, with sampling error, this must be considered a rough estimate). Figure 3 displays the probability that a family experienced negative caloric production based on the mean parental age and the number of co-resident dependents. Although young and large families would show the greatest likelihood of experiencing deficits if they had to rely on their own production, at least $20 \%$ of families would experience net caloric deficits in the absence of sharing, regardless of age and dependency combination (Figure 3). This represents a substantial level of need.

\subsection{Crop failure}

Although tropical horticulture often yields relatively predictable energetic returns, crop failure is not uncommon. In the past decade alone, there have been three years where seasonal flooding led to massive crop loss in many riverine villages. Insects, hungry animals, and drought are other important reasons for crop loss. On average each Tsimane family mantains $1.63 \pm 9.97$ hectares of land under cultivation. In the year prior to interview, $86 \%$ of interviewees lost rice (median loss of 0.03 hectares), $28 \%$ lost plantains (median loss of 0.03 hectares), $53 \%$ lost corn (median loss of 0.02 hectares), and $51 \%$ lost manioc (median loss of 0.02 hectares). Normally, these four crops comprise $96 \%$ of cultivated calories consumed, or $65 \%$ of the daily diet. In this sample, rice crops were ruined most often by insects (47\%) and aridity (32\%), plantains by flooding (79\%), corn by animals $(35 \%)$ and aridity (35\%), and manioc by animals (52\%) and flooding $(45 \%)$.

Solutions to crop failure are multifaceted. Tsimane plant a variety of seed or root types that they claim vary in their drought, flood or insect resistance, and in their productivity. Tsimane also plant fields in different locations to diversify their risk, although field 
scattering may increase travel distance, which can be burdensome especially during harvests. Tsimane also overplant to insure against some expected loss. Thus, interviewees often responded that the crop failure experienced in the past year had little impact on their consumption. When the impact was deemed large, the most common recourse was to ask for food from others or to be gifted food without asking. Help following crop failure was often received from parents, siblings and adult children (Table 2). Other kin, such as aunts, uncles and cousins, also provided assistance.

\subsection{Parental loss}

The loss of a mother or father very early in life is often associated with poor health outcomes, stunted growth and increased likelihood of death (Sear and Mace 2007; Winking et al. 2011). Among Tsimane, 16.5\% (111/671) of respondents had a parent die before reaching 18 years of age. In $10 \%$ of these cases, the respondent migrated to a different village. While in $45 \%$ of the cases people remained in the natal household with their surviving parent, many moved to live with grandparents (19\%), siblings (14\%) or other kin (19\%) such as aunts and uncles (Table 3). They were likely to be fed and cared for by kin as well. After maternal death, small children are unlikely to remain living with their father but will instead live with kin (usually maternal grandparents). After paternal death, young breastfeeding children are likely to continue living with the mother, but it is not uncommon for older children to live elsewhere; a woman with dependent children from a previous marriage has a difficult time remarrying.

Even in the absence of parental death children may live apart from biological parents. In our sample, an additional 2.5\% (17/671) lived apart from their parents during childhood or adolescence; all but one of these was a result of parental divorce. In $94 \%$ of these cases the child lived with grandparents (Table 3). Mean time spent living outside the natal home was 11.2 $\pm 5.3 \mathrm{yrs}(\mathrm{n}=91)$. The lone case of living with relatives for reasons other than parental death or divorce was to "help keep [my] grandmother company".

\subsection{Spousal loss}

The loss of a spouse by death or divorce can have a dramatic impact on health and wellbeing of household members. 8.8\% (59/671) of adults divorced and 8.9\% (60/671) had a spouse die at some point in their lives. Tsimane fertility is high (Total Fertility Rate=9), and both husbands and wives contribute substantially to household production (Gurven et al. 2009). The loss of a partner often requires migration to fill the gap until a new suitable partner can be found. Women likely experience greater costs of spousal loss given their lower remarriage rates and often need to relocate (Winking and Gurven 2011). In 54\% (32/59) of divorces, the interviewee permanently relocated to another village to live with parents (46\% of relocations), adult children (29\%), adult siblings (6\%), and other kin (11\%).

\subsection{Loss of tools and other possessions}

The Tsimane toolkit is limited but is nonetheless crucial to insure efficient resource production and food processing. Common tools include machetes, steel axes, shotguns or rifles, knives and fish hooks. It is not infrequent for these valuable tools to break given daily usage, or be stolen. In the one year recall period of the interview, 79\% and 33\% experienced the loss and theft, respectively, of a household item. Table 4 itemizes the most frequently broken or stolen items. Machetes, shotguns and rifles, and canoes are commonly ruined. While theft is less common than breakage, people complained most about the theft of clothes $(13 \%)$, domesticated chickens (11\%), machetes, fish hooks and cutlery (6\% each) (Table 4). 
Helping is somewhat limited when resources are lost or stolen. The most common response is to do nothing, or to replace an item oneself by making or purchasing another. If an adult does not have another item to use to replace the broken or stolen one, he or she is likely to borrow the item (e.g. $8 \%$ borrowed machetes, $11 \%$ borrowed shotguns/rifles, and $54 \%$ borrowed canoes) (Table 4$)$.

\subsection{Social conflict}

While social living brings many benefits to individuals, and while kinship helps structure the direction and magnitude of transfers, frequent interaction with kin (among other reasons such as genetic conflict) can also lead to conflicts of interest. Such conflicts can create rifts among individuals, and reduce the potential to reap the gains of cooperation. $17 \%$ of interviewees (41/239) reported having a serious conflict in the past three months and $79 \%$ $(93 / 239)$ in the past year. Women report most conflicts with their husband (29\%), adult siblings $(26 \%)$ and other kin $(29 \%)$, while men report most conflicts with distant kin (22\%) and non-kin $(61 \%)$ (Table 5). Gossip with the potential to damage reputation is touted as one of the most important concerns for both sexes (Table 6). Men report skirmishes with other men while intoxicated as most common, often with little provocation or obvious motive. Women report spousal conflict and jealous arguments concerning choosing and retaining mates.

Respondents were likely to receive some type of support or assistance for 48\% (114/239) of the reported conflicts. Parents and distant kin were most likely to intervene on behalf of women, while distant kin and non-kin intervened more on behalf of men (Table 5). The likelihood of mediation varied by conflict type. Conflicts over gossip, mate choice, drunkenness, exploitation by others and theft are likely to receive assistance (Table 6). These conflicts are likely to carry serious consequences for all parties involved, and so their resolution can be of profound importance.

\subsection{Summing across categories: estimating age-specific value}

We construct a new age-specific productivity profile for the other categories of helping based on the ages of named donors (Figure 4). For each category of helping, $h$, the frequency of donors in age group $i$ (where $i=20-39,40-59$ and 60+ years), $f_{h}(i)$, was calculated and divided by the representation of age group $i$ in the population using census estimates. Values of $f_{h}(i)$ were normalized within each helping category $h$ to the maximum value, thereby facilitating comparisons of the relative contributions made by a typical member of each age group. Adults over the age of 40, and even those over the age 60 are routinely named as having helped in a variety of tasks pertaining to incapacitating illness or injury, crop failure, and conflict resolution (Figure 4). While older adults also frequently adopt small children as a result of parental divorce or death, we did not have records on the ages at which older adults adopted those children and so could not include this important category in Figure 4, but including it would further increase the value of older people.

Figure 5 plots Fisher's reproductive value $\left(R_{X}\right)$ to illustrate the expected future reproduction at each age given the Tsimane population age structure, mortality rates averaged across sexes $\left(q_{X}\right)$ and female fertility $\left(m_{X}\right)$ schedules published in Gurven et al. (2007). We also plot a caloric production value $V_{X}$ analogous to $R_{X}$, but replace age-specific female fertility $m_{X}$ with age-specific caloric production averaged across males and females. This measure provides the expected future caloric production conditional on survival to age $x$. While $R_{X}$ begins its steep descent from its peak at age 15 to near zero by age $45, V_{X}$ doesn't reach zero until about age 80 . By age $45, V_{X}$ is still $57 \%$ of its peak value, and $24 \%$ of its peak by age 60. For comparison, $R_{X}$ and $V_{X}$ for wild chimpanzees show a similar age pattern of decline. Given the ubiquity of food transfers among humans within and across generations, 
particularly to close kin, the high production value in late adulthood greatly increases fitness impacts of older adults.

\section{Discussion and Conclusion}

Tsimane lives are rife with risk at all ages due to food shortage, illness, injury, kin and partner death, conflict and theft. Risk from each of these categories has the potential to significantly impact survival and/or fertility. Because of these risks, Tsimane reduce risk and smooth the bumps created by risk through high levels of sociality. But sharing is not indiscriminate. We find that spouses and close kin such as parents, offspring and siblings are consistently the main sources of support in each of the domains described in this paper. This reliance on kin is a common theme in ethnographies of small-scale societies without access to private markets. Living near kin and maintaining access to kin and investing in reputation are important components of social capital. Social capital, based largely on kinship and to some extent reciprocity, is a critical but understudied resource among small-scale societies (Smith et al. 2010).

We propose that human sociality serves to reduce risk-in the short-term for managing daily shortfalls, and on longer time scales for feeding dependents, handling illness and managing other types of risk. Risk reduction was necessary for sustaining a foraging way of life and is a central component of the evolved human life history. But the question remains as to how humans diverged from other hominins and why others did not follow the same path. For example, while wild chimpanzees share food and other resources (Mitani and Watts 2001), most food transfers are passive (Jaeggi and van Schaik 2011), chimpanzees rarely live beyond age 45, the age when humans reach peak net economic productivity, and chimpanzee grandparents are rarely observed helping anyone (Goodall 1986).

Apes and hominins diverged in the Pliocene, distinguished most prominently by their respective modes of locomotion, and their relative efficiencies in arboreal and terrestrial locomotion, respectively. Among ancestral hominins, early bipedalism, longer day ranges and more efficient terrestrial locomotion also likely pushed for greater hunting and gathering specialization, and a reliance on large-packaged but relatively high-variance foods (Kaplan et al. 2000). During the drying of the Pleistocene and the expansion of African savannahs, these hominins would have been 'pre-adapted' to better reap the gains from increased specialization on the mammal species, roots and nuts which proliferated during this period. Sociality early in human evolution likely reduced mortality from predation, poor health and economic risks. This initial lowering of mortality is analogous to "extrinsic" mortality reduction that thereby selects for further investment in reducing adult mortality rates. With a greater probability of reaching adulthood, selection would then have favored further specialization toward skill-intensive foraging subsistence strategies with delayed returns, and a higher rate of intergenerational transfers (Kaplan and Robson 2002). Regardless of the original benefits of sociality, the mortality-lowering effect of social support should thus have pushed early hominins towards greater foraging specialization, extended development and survivorship to produce and support kin at higher levels later in life.

Older Tsimane provide valuable contributions including mediation of conflicts among kin, adoption of kin after parental or spousal death or divorce, assistance during illness and injury, compensation after crop failure, and helping to subsidize large families of close kin. Older adults may also play important roles as influential leaders and educators of important skills. Given cultural transmission within and across generations, transfers also include information in addition to the more traditional emphasis on food and materials (Schniter 2009). Measuring the frequency, impact and direction of these broader transfers is important for estimating the fitness-impact of older adults, and ultimately the value of being alive at 
each age. The greater the fitness value of life at late ages, the greater the force of selection on investing in further mortality reduction due to its higher marginal benefit (Kaplan and Robson 2009). To date, "production" in small-scale societies has been defined mostly in terms of daily caloric production, due to the fundamental importance of energetics, and also because it is relatively easy to measure in field studies. Another useful approach incorporates other economic contributions such as food processing and other tasks indirectly linked to caloric production (Lee and Kramer 2002).

Our paper advances the field by systematically describing risks, and their social solutions via transfers. The results presented here are likely to generalize to other groups of smallscale subsistence societies, although some aspects may differ. The presence of horticulture among Tsimane enables older adults to produce more calories relatively late in life, in comparison to older adults in hunter-gatherer societies (Howell 2010; Marlowe 2010), and likely accounts for the very high fertility of Tsimane. Despite these differences, there are important similarities amongst these populations in terms of caloric production and sickness. Early life caloric deficits are common in all examined forager and horticulturalist groups, and multiple dependents take their toll on household net production as we observed among Tsimane. For example, roughly half of Ache families and 11 out of 19 Hiwi families consume more calories than they produce (Hill and Hurtado 2009: Figure 4). Net caloric deficits are also common among Dobe !Kung families (Howell 2010). Similarly, Ache and Efe foragers are reported sick on 21\% of sampled days (Bailey 1991; Hill and Hurtado 2009); Yora and Shiwiar hunter-horticulturalists are sick on $8 \%$ of all days (Sugiyama and Chacon 2000). These groups are known for varying degrees of cooperative behavior and extensive food sharing. Although other types of risk have not been systematically surveyed in these populations, we suspect that future studies will reveal similar levels of risk and social support focused on minimizing that risk.

Future work will focus on the magnitude of kin-based transfers to assess the extent to which late-age contributions are optimally directed so as to maximize fitness. The approach of Kaplan and Robson (2009), for example, assumed clonal reproduction and hence all transfers were to genetically identical individuals. Lee (2008) simulates the effects of several sharing arrangements and demonstrates the importance of kin versus non-kin transfers on both infant and post-reproductive survival. Upward transfers from younger to older adults require additional investigation, as the traditional focus has been on net flows downward from older to younger generations. While upward transfers are common, we expect these to occur when older adults are net producers in like or other currencies. We suspect that the decline in caloric production at late ages is offset by older adults' other contributions for perhaps another decade, but then total overall value declines rapidly by the eighth decade of life. The decline in value at these late ages, accompanied by rapidly rising mortality rates is consistent with Kirkwood's disposable soma theory (Kirkwood 1990). Transfers and support to older adults in their 80's are expected to be rare, with overt or covert geronticide or suicide (Maxwell et al. 1984) as a consequence of extreme frailty and being a net cost to kin. It does appear, however, that it is only when people are approaching death that their productivity drops below their consumption. It is likely that those who live into very old age (greater than age 70 for foragers) will tend to be the most robust and healthy of their cohort.

\section{Acknowledgments}

We are grateful to the Tsimane for their collaboration and hospitality. Funding was provided by the National Institutes of Health/National Institutes on Aging (R01AG024119, R56AG024119, P01AG022500) and the National Science Foundation (BCS0136274, BCS0422690). 


\section{References}

Amdam GV, Page RE. Intergenerational transfers may have decoupled physiological and chronological age in a eusocial insect. Ageing research reviews. 2005; 4(3):398-408. [PubMed: 16039913]

Bailey, RC. The Behavioral Ecology of Efe Pygmy Men in the Ituri Forst, Zaire. University of Michigan, Museum of Anthropology; 1991.

Baudisch A. Hamilton's indicators of the force of selection. Proceedings of the National Academy of Sciences of the United States of America. 2005; 102(23):8263. [PubMed: 15919822]

Black FL. Infectious disease in primitive societies. Science. 1975; 187(4176):515-518. [PubMed: 163483]

Black FL, Woodall JP, Evans AS, Liebhaber H, Henle G. Prevalence of antibody against viruses in the Tiriyo, an isolated Amazonian tribe. American Journal of Epidemiology. 1970; 91:430-438. [PubMed: 4316199]

Bourke AFG. Kin selection and the evolutionary theory of aging. Annu Rev Ecol Evol Syst. 2007; 38:103-128.

Carey, JR.; Gruenfelder, C. Population biology of the elderly. In: Wachter, KW.; Finch, CE., editors. Between Zeus and the Salmon. Washington D.C: National Academy Press; 1997. p. 127-160.

Cyrus Chu C, Lee RD. The co-evolution of intergenerational transfers and longevity: An optimal life history approach. Theoretical Population Biology. 2006; 69(2):193-201. [PubMed: 16406044]

Donovan B. The repertoire of human efforts to avoid sexually transmissible diseases: past and present. Part 1. Strategies used before or instead of sex. Sex Transm Infect. 2000; 76:88-93. [PubMed: 10858708]

Emery Thompson M, Jones JH, Pusey AE, Brewer-Marsden S, Goodall J, Marsden D, Matsuzawa T, Nishida T, Reynolds V, Sugiyama Y, et al. Aging and fertility patterns in wild chimpanzees provide insights into the evolution of menopause. Current Biology. 2007; 17:2150-2156. [PubMed: 18083515]

Finch CE, Stanford CB. Meat-Adaptive Genes and the Evolution of Slower Aging in Humans. Quarterly Review of Biology. 2004; 79(1):3-50. [PubMed: 15101252]

Galef BG. Social influences on foraging in vertebrates: causal mechanisms and adaptive functions. Animal Behaviour. 2001; 61(1):3-15. [PubMed: 11170692]

Goncalves ML, Araujo A, Ferreira LF. Human intestinal parasites in the past: new findings and a review. Mem Inst Oswaldo Cruz. 2003; 98:103-118. [PubMed: 12687769]

Goodall, J. The Chimpanzees of the Gombe: Patterns of Behavior. Cambridge: Cambridge University Press; 1986.

Gurven M. To give or to give not: an evolutionary ecology of human food transfers. Behavioral and Brain Sciences. 2004; 27(4):543-583.

Gurven M, Kaplan H, Gutierrez M. How long does it take to become a proficient hunter? Implications for the evolution of delayed growth. Journal of Human Evolution. 2006; 51:454-470. [PubMed: 16797055]

Gurven M, Kaplan H, Zelada Supa A. Mortality experience of Tsimane Amerindians: regional variation and temporal trends. American Journal of Human Biology. 2007; 19:376-398. [PubMed: 17421012]

Gurven M, Winking J, Kaplan H, von Rueden C, McAllister L. A bioeconomic approach to marriage and the sexual division of labor. Human Nature. 2009; 20(2):151-183.

Gurven MD, Kaplan HS. Determinants of time allocation to production across the lifespan among the Machiguenga and Piro Indians of Peru. Human Nature. 2006; 17(1):1-49.

Hamilton WD. The genetical evolution of social behavior. Journal of Theoretical Biology. 1964; 7:152. [PubMed: 5875341]

Hill K, Boesch C, Goodall J, Pusey A, Williams J, Wrangham R. Mortality rates among wild chimpanzees. Journal of Human Evolution. 2001; 40:437-450. [PubMed: 11322804]

Hill K, Hurtado AM. Cooperative breeding in South American hunter-gatherers. Proceedings of the Royal Society B: Biological Sciences. 2009; 276(1674):3863. 
Hooper, PL. PhD Dissertation. Albuquerque, NM: University of New Mexico; 2011. The structure of energy production and redistribution among Tsimane' forager-horticulturalists.

Howell, N. Life histories of the Dobe! Kung: food, fatness, and well-being over the life span. Univ of California Press; 2010.

Hurtado, AM.; Anderson Frey, M.; Hurtado, I.; Hill, K.; Baker, J. The role of helminthes in human evolution: implications for global health in the 21 st century. In: Elton, S.; O'Higgins, P., editors. Medicine and Evolution: Current applications, future prospects. New York: Taylor and Francis; 2008. p. 151-178.

Jaeggi AV, van Schaik CP. The evolution of food sharing in primates. Behavioral Ecology and Sociobiology. 2011; 65:2125-2140.

Kaplan H. Evolutionary and wealth flows theories of fertility: empirical tests and new models. Population and Development Review. 1994; 20(4):753-791.

Kaplan H, Hill K, Lancaster JB, Hurtado AM. A theory of human life history evolution: Diet, intelligence, and longevity. Evolutionary Anthropology. 2000; 9(4):156-185.

Kaplan HS, Robson AJ. The emergence of humans: the coevolution of intelligence and longevity with intergenerational transfers. Proceedings of the National Academy of Sciences. 2002; 99:1022110226.

Kaplan HS, Robson AJ. We age because we grow. Proceedings of the Royal Society Biological Sciences. 2009; 276(1663):1837-1844. [PubMed: 19324786]

Kirkwood, TBL. The disposable soma theory of aging. In: Harrison, DE., editor. Genetic Effects on Aging II. Caldwell, N.J: Telford Press; 1990. p. 9-19.

Lee, R. Seminar on intergenerational economic relations and demographic change: papers. Liege, Belgium: International Union for the Scientific Study of Population [IUSSP], Commitee on Economic Demography; 1996. A cross-cultural perspective on intergenerational transfers and the economic life cycle; p. 1-25.

Lee RD. Rethinking the evolutionary theory of aging: Transfers, not births, shape senescence in social species. PNAS. 2003; 100(16):9637-9642. [PubMed: 12878733]

Lee RD. Sociality, selection and survival: simulated evolution of mortality with intergenerational transfers and food sharing. PNAS. 2008; 105(20):7124-7128. [PubMed: 18458325]

Lee RD, Kramer KL. Children's Economic Roles in the Maya Family Life Cycle: Cain, Caldwell, and Chayanov Revisited. Population and Development Review. 2002; 28(3):475-499.

Marlowe, F. The Hadza: hunter-gatherers of Tanzania. Univ of California Press; 2010.

Maxwell, RJ.; Silverman, P.; Maxwell, EK. The Motive for Geronticide. In: Sokolovsky, J., editor. Special issue, Studies in Third World Societies, No 22. Williamsburgh: William and Mary College; 1984. p. 67-83.

McKeown, T. The Modern Rise of Population. New York: Academic Press; 1976.

Mitani JC, Watts DP. Why do chimpanzees hunt and share meat? Animal Behaviour. 2001; 61(5):915924.

Pearce-Duvet JMC. The origin of human pathogens: evaluating the role of agriculture and domestic animals in the evolution of human disease. Biological Reviews. 2006; 81:369-382. [PubMed: 16672105]

Robson A, Kaplan H. The co-evolution of longevity and intelligence in hunter-gatherer economies. American Economic Review. 2003; 93:150-169.

Salzano, FM.; Callegari-Jacques, S. Research Monographs on Human Population Biology. Oxford University Press; 1988. South American Indians: a case study in evolution.

Schniter, E. PhD Dissertation. Santa Barbara: University of California-Santa Barbara; 2009. Why Old Age: Non-material contributions and patterns of aging among older adult Tsimane'.

Sear R, Mace R. Who keeps children alive? A review of the effects of kin on child survival. Evolution and Human Behavior. 2007; 29(1):1-18.

Smith EA, Hill K, Marlowe F, Nolin D, Wiessner P, Gurven M, Bowles S, Mulder MB, Hertz T, Bell A. Wealth transmission and inequality among hunter-gatherers. Current Anthropology. 2010; 51(1):19. [PubMed: 21151711]

Stearns, SC. The Evolution of Life Histories. Oxford: Oxford University Press; 1992. 
Sugiyama, L.; Chacon, R. Effects of illness and injury on foraging among the Yora and Shiwar: Pathology risk as adaptive problem. In: Cronk, L.; Irons, W.; Chagnon, N., editors. Human Behavior and Adaptation: An Anthropological Perspective. New York: Aldine de Gruyter; 2000.

Trivers RL. The evolution of reciprocal altruism. Quarterly Review of Biology. 1971; 46:35-57.

Winking J, Gurven M. The total cost of father desertion. American Journal of Human Biology. 2011; 23(6):755-763. [PubMed: 21932418]

Winking J, Gurven M, Kaplan H. The Impact of Parents and Self-Selection on Child Survival among the Tsimane of Bolivia. Current Anthropology. 2011; 52(2):277-284.

Winterhalder B. Social foraging and the behavioral ecology of intragroup resource transfers. Evolutionary Anthropology. 1997; 5:46-57. 


\section{HIGHLIGHTS}

- Risk is rife among human foragers, due to hunger, illness, death and conflict

- Resource transfers reduce risk and adults age 40+ are major sources of aid

- Spouses and close kin are preferred targets of assistance

- Transfers reduce mortality rate and favor selection on post-reproductive lifespan 


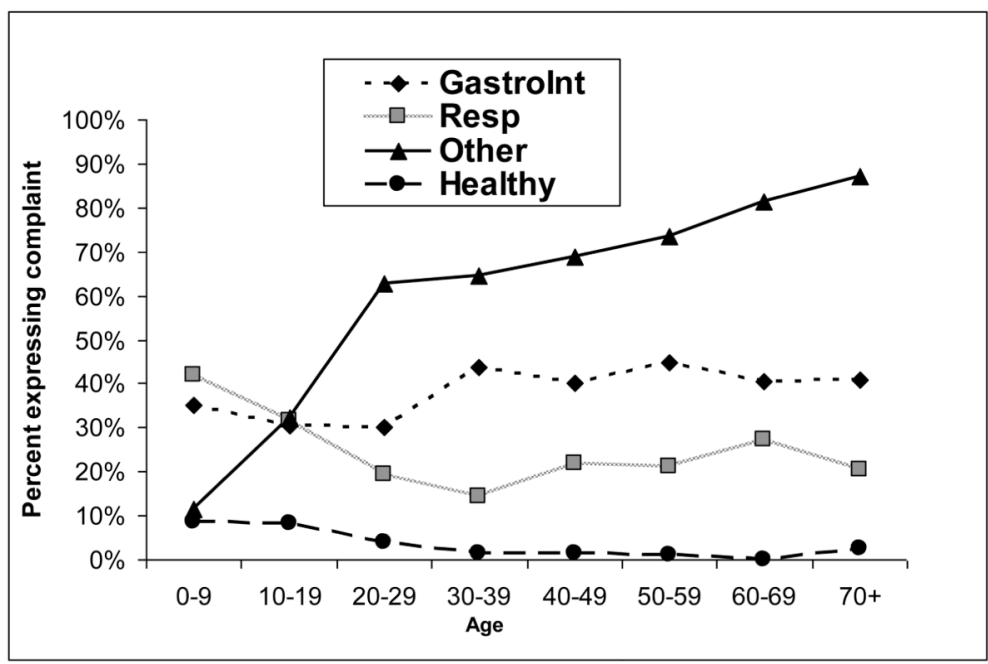

Figure 1.

Probability of being diagnosed with gastrointestinal, respiratory infection or other ailment during routine annual medical exams $(n=2,828)$, as part of the Tsimane Health and Life History Project (THLHP). 


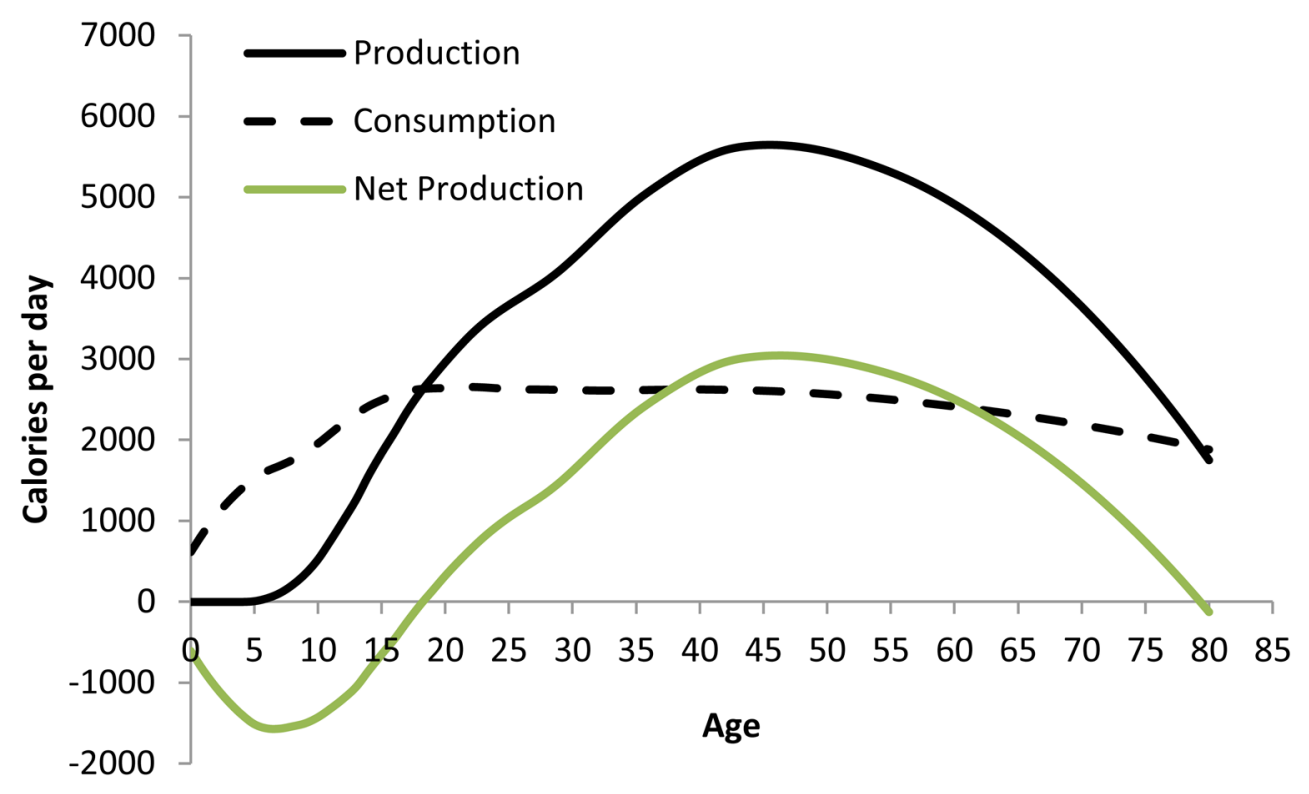

Figure 2.

Tsimane daily food production, consumption and net production (calories/day). 


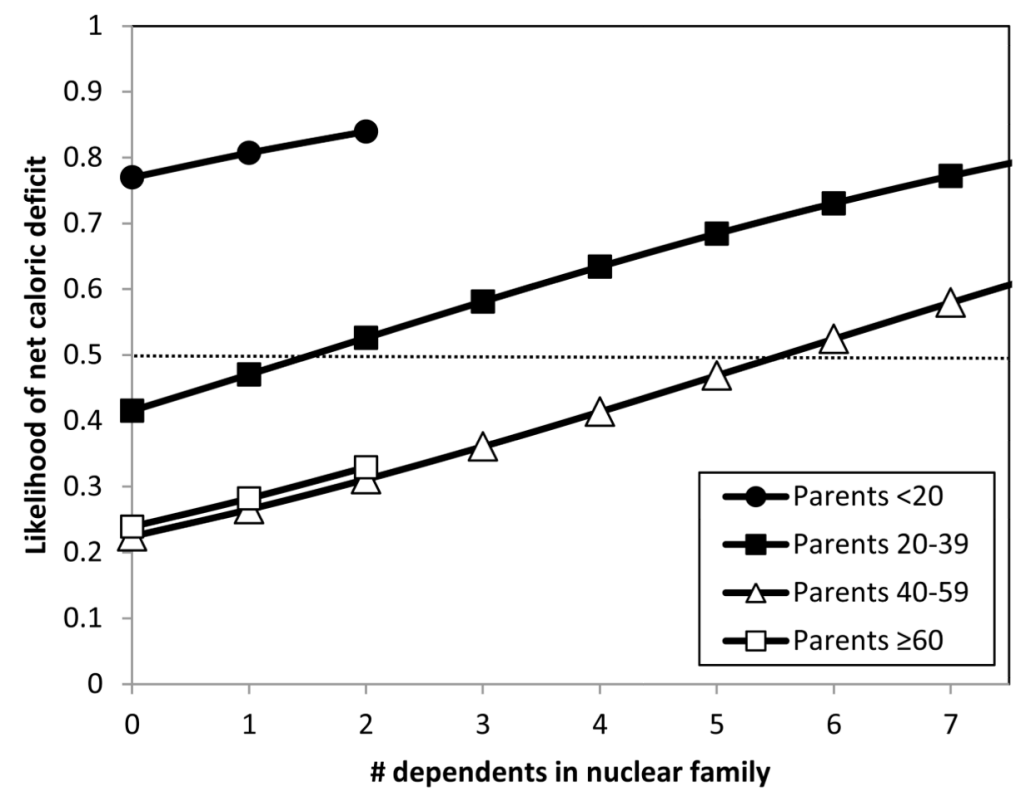

Figure 3.

Probability of a net caloric deficit in a nuclear family as a function of the mean age of parents and the number of co-resident dependents (defined here as those $<18$ years old). Estimates derived from logistic regression (AIC=244.13). No interaction terms were significant at the $a=0.05$ level. 


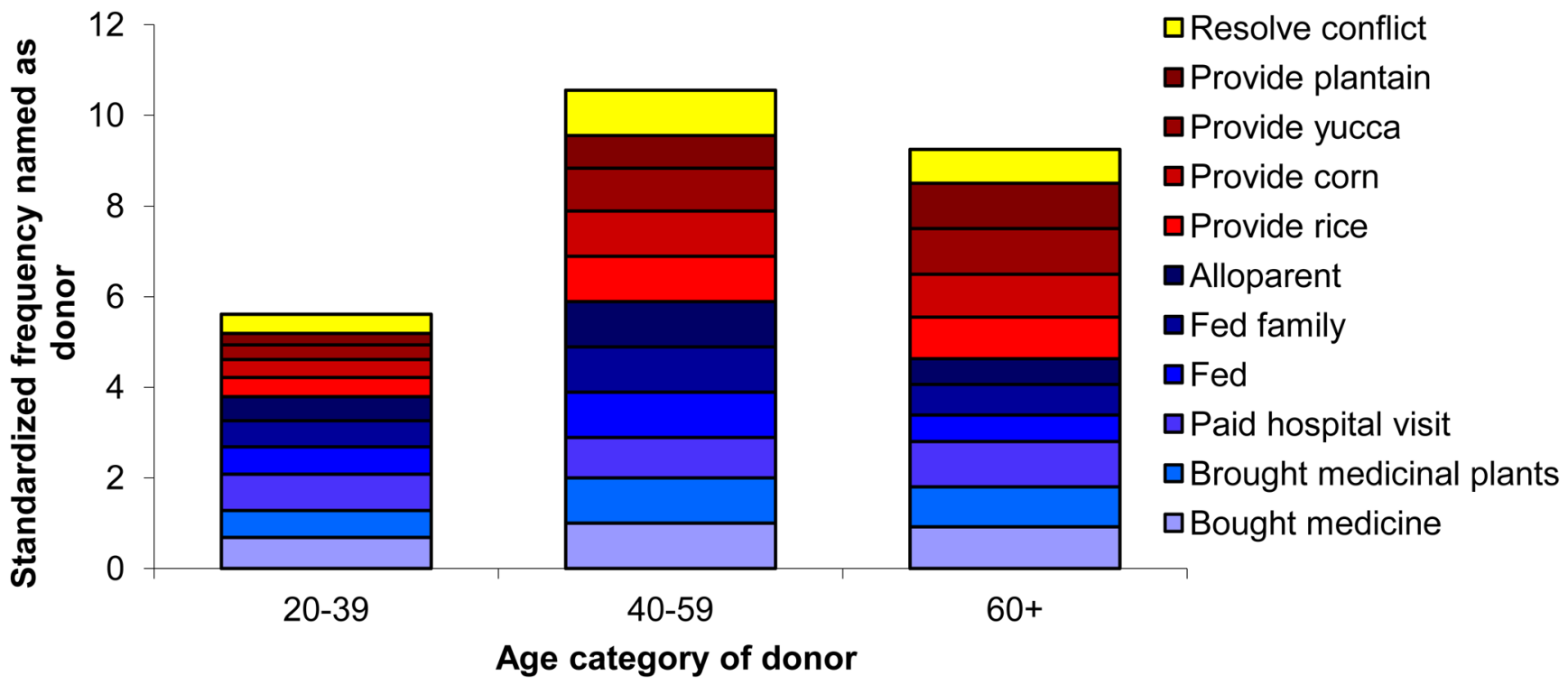

Figure 4.

Age-specific production for three macro-categories: (a) conflict resolution, (b) assistance during crop failure, (c) assistance during incapacitating sickness or injury 


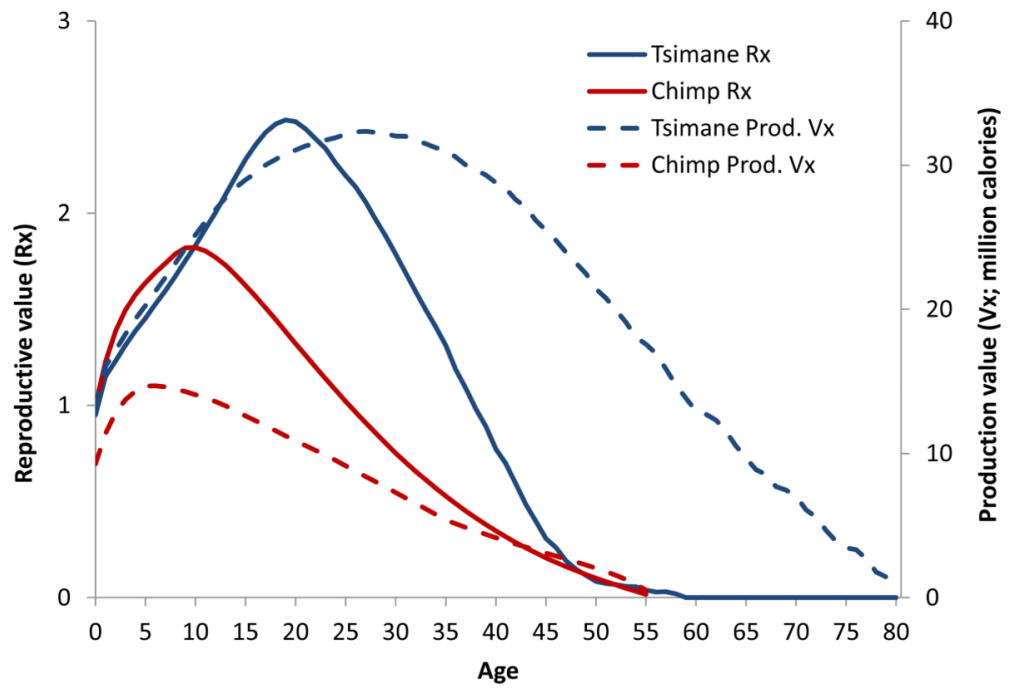

Figure 5.

Reproductive and productive value among Tsimane and wild chimpanzees. Chimpanzee mortality and fertility data come from Hill et al. (2001) and Emery Thompson et al. (2007: Table S1), respectively. 


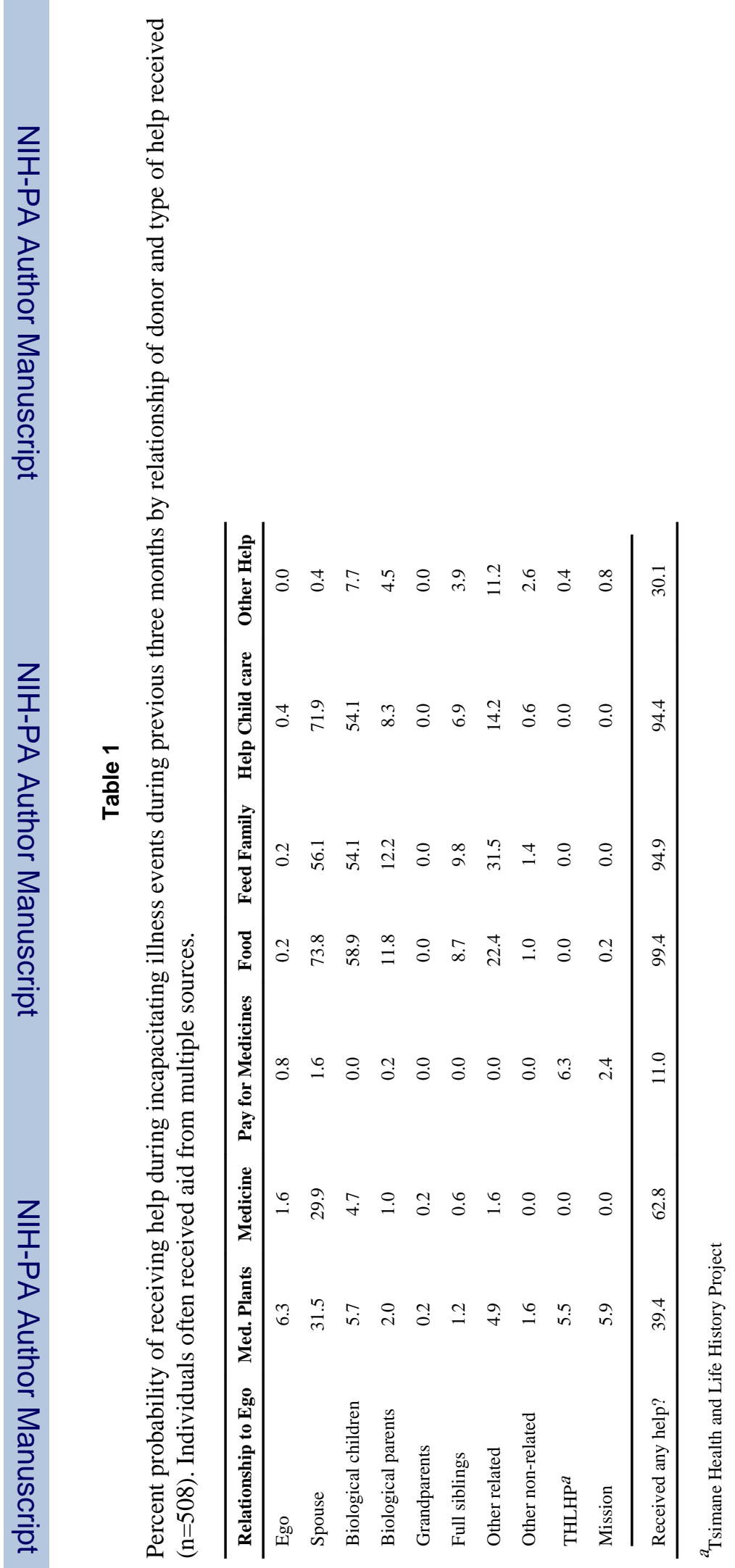

Exp Gerontol. Author manuscript; available in PMC 2013 October 01. 


\section{Table 2}

Help received following crop failure in previous year. Excluded are cases where the loss was claimed to have little or no effect on consumption. Help was often given by multiple kin categories and so the bottom row reflects the percentage of interviewees who received help from at least one donor category.

\begin{tabular}{lcccc}
\hline & \multicolumn{4}{c}{ \% Help Received } \\
\cline { 2 - 5 } & Rice $(\mathbf{n}=\mathbf{3 7 4})$ & Corn $(\mathbf{n = 4 3 3})$ & Manioc $(\mathbf{n = 3 3 0})$ & Plantain $(\mathbf{n}=\mathbf{2 8 5})$ \\
\hline Biological children & 21.5 & 15.6 & 15.4 & 14.1 \\
Biological parents & 24.4 & 21.8 & 24.3 & 19.6 \\
Grandparents & 1.5 & 1.2 & 1.1 & 1.0 \\
Full siblings & 18.9 & 20.0 & 19.3 & 17.6 \\
Other related & 52.4 & 51.5 & 50.0 & 55.8 \\
Other non-related & 9.1 & 9.7 & 11.1 & 10.6 \\
Received help from anyone & 73.5 & 78.5 & 84.8 & 69.8 \\
\hline
\end{tabular}


Table 3

Co-residence and feeding by relationship category upon parental death or divorce. The relevant risk period here reflects the first eighteen years of life.

\begin{tabular}{lccc}
\hline & \multicolumn{2}{c}{ Death of parent } & Parental divorce \\
\cline { 2 - 4 } Kin category of helper & co-resident $\%(\mathbf{n}=\mathbf{1 2 1})$ & fed by $\%(\mathbf{n}=\mathbf{1 3 2})$ & co-resident $\%(\mathbf{n}=\mathbf{1 7})$ \\
\hline Biological parent & 45.5 & 14.4 & 0.0 \\
Grandparents & 19.0 & 20.5 & 94.1 \\
Full siblings & 14.0 & 27.3 & 0.0 \\
Other related & 19.0 & 35.6 & 5.9 \\
Other non-related & 2.5 & 2.3 & 0.0 \\
\hline
\end{tabular}




\section{Table 4}

Probability of (a) resource loss and theft in the past year and (b) receiving assistance from others following the loss.

\begin{tabular}{lcccc}
\hline & \multicolumn{2}{c}{ Loss } & \multicolumn{3}{c}{ Help } \\
\cline { 3 - 6 } Type of loss & $\#$ & $\%$ & $\#$ & $\%$ \\
\hline Broken & & & & \\
Machete & 453 & 69 & 36 & 8 \\
Rifle/shotgun & 245 & 37 & 28 & 11 \\
Canoe & 56 & 8 & 30 & 54 \\
Theft & & & & \\
Clothes & 83 & 13 & 0 & 0 \\
Chickens & 73 & 11 & 2 & 3 \\
Machete & 42 & 6 & 1 & 3 \\
Fish hooks & 38 & 6 & 0 & 0 \\
Knife/spoon/plate & 37 & 6 & 0 & 0 \\
Canoe & 28 & 4 & 0 & 0 \\
Yarn/string & 27 & 4 & 0 & 0 \\
\hline
\end{tabular}


Table 5

Social conflicts reported by men and women over year prior to interview.

\begin{tabular}{lcccc}
\hline & \multicolumn{2}{c}{ With whom? } & \multicolumn{2}{c}{ Who helped? } \\
\cline { 2 - 5 } Sex of interviewee: & Men \% & Women \% & Men \% & Women \% \\
Relationship to ego & $(\mathbf{n = 1 2 0})$ & $(\mathbf{n = 1 1 9 )}$ & $(\mathbf{n = 1 2 1})$ & $(\mathbf{n = 1 2 2})$ \\
\hline None & $\mathrm{n} / \mathrm{a}$ & $\mathrm{n} / \mathrm{a}$ & 48.8 & 54.1 \\
Spouse & 2.5 & 28.6 & 0.8 & 7.4 \\
Biological children & 2.5 & 2.5 & 1.7 & 5.7 \\
Biological parents & 2.5 & 2.5 & 5.0 & 10.7 \\
Grandparents & 0.0 & 0.0 & 1.7 & 0.8 \\
Full siblings & 6.7 & 26.1 & 5.8 & 8.2 \\
Other related & 22.5 & 28.6 & 16.5 & 10.7 \\
Other non-related & 60.8 & 11.8 & 19.8 & 2.5 \\
\hline
\end{tabular}

Exp Gerontol. Author manuscript; available in PMC 2013 October 01. 
Table 6

Sources of conflict reported by men and women

\begin{tabular}{lcccc}
\hline & \multicolumn{2}{c}{ Men } & \multicolumn{2}{c}{ Women } \\
\cline { 2 - 5 } Reason for conflict & \% (n=120) & \% w/help (n=61) & \% (n=119) & \% w/help (n=53) \\
\hline Drunkenness & 25.0 & 36.7 & 6.7 & 62.5 \\
Gossip & 21.7 & 69.2 & 19.3 & 52.2 \\
Mate choice & 10.8 & 76.9 & 21.8 & 34.6 \\
Exploitation by others (jatata/wood/land) & 9.2 & 45.5 & 5.0 & 16.7 \\
Stinginess & 7.6 & 55.6 & 5.9 & 42.9 \\
Theft & 7.5 & 44.4 & 5.0 & 33.3 \\
Money & 7.5 & 55.6 & 0.8 & 100.0 \\
Marital & 2.5 & 0.0 & 22.7 & 40.7 \\
Residence & 2.5 & 0.0 & 0.8 & 100.0 \\
Soccer & 1.7 & 100.0 & 0.0 & \\
Work effort, non-marital & 0.8 & 0.0 & 3.4 & 50.0 \\
Illness contagion & 0.0 & & 0.8 & 0.0 \\
Visitation & 0.0 & & 1.7 & 100.0 \\
\hline
\end{tabular}

Exp Gerontol. Author manuscript; available in PMC 2013 October 01. 